\title{
Effectiveness of the behavior change intervention to improve harm reduction self-efficacy among people who inject drugs in Thailand
}

This article was published in the following Dove Press journal:

Psychology Research and Behavior Management

6 September 2016

Number of times this article has been viewed

\author{
Duangta Pawa' \\ Chitlada Areesantichai ${ }^{1,2}$ \\ 'College of Public Health Sciences, \\ Chulalongkorn University, ${ }^{2}$ Drug \\ Dependence Research Center WHO \\ Collaborating Centre for Research \\ and Training in Drug Dependence, \\ Bangkok, Thailand
}

Background: People who inject drugs (PWID) in Thailand reported unsafe injection practices resulting in injection-related health consequences. Harm reduction self-efficacy plays an important role and could be improved to reduce harm associated with injecting drugs. Evidence-based interventions targeting PWID are needed. This study sought to evaluate the effectiveness of the behavior change intervention within the PWID population.

Methods: The behavior change intervention, Triple-S, was designed to improve harm reduction self-efficacy among PWID. This quasi-experimental study was a pre- and post-comparison with a control group design. Participants were PWID, aged 18-45 years, and located in Bangkok. Changes in harm reduction self-efficacy of the intervention group were compared with the control group using paired and independent $t$-test.

Results: Most of PWID were male (84\%), had a secondary school and lower education (71\%), were single, and had a mean age of 41 years. They had been injecting drugs for an average of 20 years, and the median of drug injections per week was ten times in the past month. Pre- and post-intervention effects were measured and results showed that the intervention group reported improvement in harm reduction self-efficacy in negative emotional conditions $(P=0.048)$.

Conclusion: Our findings suggest that Triple-S intervention can significantly improve harm reduction self-efficacy in negative emotional conditions. The results may suggest the importance of behavior change intervention, especially when integrated with services provided by drop-in centers. The intervention can be further developed to cover other harm reduction behaviors and improve harm reduction self-efficacy.

Keywords: drug injection, harm reduction, self-efficacy, behavior change, drug use, substance abuse

\section{Background}

Intravenous drug use is driving human immunodeficiency virus (HIV) epidemics with negative health consequences in many countries around the world. The United Nations Office on Drugs and Crime reported that three million people who inject drugs (PWID) are affected by the HIV epidemic worldwide. ${ }^{1}$ Additionally, the blood-borne viral infections, hepatitis $\mathrm{B}$ virus and hepatitis $\mathrm{C}$ virus, were the main causes of health problems. ${ }^{2}$ PWID with long history of injecting drugs faced increased risks of overdose and higher incidences of injection-related health issues. These issues included septicemia, bacterial endocarditis and osteomyelitis, and local soft tissue and vascular injuries such as skin abscesses and thrombophlebitis. ${ }^{3,4}$

In Thailand, the illegality of injecting drugs, as well as high levels of stigma associated with PWID, means that information on PWID in Thailand is limited. A recent estimate of the total number of PWID in Thailand was $40,300 .^{5}$ A 2009 estimate of the PWID
Correspondence: Duangta Pawa College of Public Health Sciences, Chulalongkorn University, Institute Building 3 (I0th-I I th Floor), Chulalongkorn soi 62, Phyathai Road, Bangkok 10330, Thailand

Email duangtap@gmail.com 
population in Bangkok was 4,200. ${ }^{6} \mathrm{HIV}$ prevalence among PWID in Bangkok for 2010 was reported to range from $11 \%$ to $24 \%{ }^{7}$ The PWID population in Bangkok reported high risks of HIV due to sharing needles and injecting equipment and practicing unsafe sex. ${ }^{8}$ Regarding unsafe injection practices, $34 \%$ of PWID in Bangkok reported injections at the groin. ${ }^{9}$

There are many kinds of behavioral interventions that can be implemented to assist PWID that aim to promote drug abstinence. These include cognitive behavioral therapy, ${ }^{10}$ motivational interviewing, ${ }^{11}$ and motivational enhancement therapy. ${ }^{12}$ Social cognitive learning theory was proposed for usage with drug users to address craving and relapse. ${ }^{13}$ This is a major theory for promoting behavior change and improving self-efficacy. ${ }^{14,15}$ Many studies have shown that self-efficacy is a predictor of treatment outcomes and plays an important role in stopping drug use and preventing relapse. ${ }^{16}$ While many drug users do not initially wish to stop, harm reduction approach is embraced to reduce the harms associated with drug use and implied to the treatment of drug users in terms of matching with their needs and applying more appropriate therapy format. ${ }^{17}$ Harm reduction approaches aim to prevent the spread of infections, reduce the risk of overdose, and decrease the negative effects of drug use. ${ }^{18,19}$ Strategies to reduce individual harms include reducing the amount of drugs consumed, avoiding using drugs alone, using a different vein every time to inject, and always use new injecting equipment. ${ }^{20}$ In order to reduce harms associated with injecting drugs, especially in high-risk situations, harm reduction self-efficacy could be improved to build PWIDs belief in their ability to change their behaviors. ${ }^{21,22}$

In Thailand, a number of social and structural factors appear to be driving drug use problems, including the limited availability of evidence-based interventions targeting PWID. ${ }^{23}$ Therefore, the Triple-S behavior change intervention program was designed with a focus on behavior change theories. The intervention focuses on enhancing participants' motivation to adopt safer behavior and reduce their drug use through a process of observation, positive reinforcement, practicing, and sustaining behavior change. This study sought to evaluate the effectiveness of Triple-S intervention among PWID in Bangkok, Thailand. Results were expected to show that the intervention group would be more efficacious than the control group in terms of improving harm reduction self-efficacy.

\section{Methods}

\section{Intervention}

The behavior change intervention, Triple-S, was designed grounded in social cognitive learning theory and transtheo- retical model, aimed to change PWID behaviors and improve their harm reduction self-efficacy. It consists of three parts: start, smart, and strong. Start I session prepared participants for Triple-S sessions by discussing about their life situations and drug use problems. Life goals and expectation for attending this intervention were defined. Start II session aimed to make study participants observe their own behaviors and consider changing their drug use behavior. The interventionists assessed and built the study participant's motivation to change by addressing how drug use affected their life goal. Harm reduction knowledge and concept were also given to study participants. Smart I session provided knowledge and information for changing their drug use behavior. Study participants defined their drug use behavior that they intended to change, benefits to their life, and set plan for behavior change. Role model of each person was discussed to support attention, retention, and production process. Smart II session was conducted with the aim of developing their skills to deal with challenges that occurred during behavior change process and assisted each participant to develop emergency plan in order to cope with relapse and maintain their behavior change. Factors that were associated with relapse were discussed with study participants, including peer pressure, and family, community, and employer support. Key person support was identified in order to assist them during the process. Planning for stronger coping strategies with atrisk situations including withdrawal, negative emotions, and social conditions, were defined and various situations that caused relapse were shown with possible solutions. Strong I session addressed benefits of behavior change and enhanced their motivation by emphasizing that injecting drug could affect their life goals. Environmental factors that cause at-risk situations were given and discussed possible solutions. Strong II session focused on creating commitment for sustaining behavior change by assisted each participant to realize advantages of behavior change that lead to their life goals, belief in their capability to change and deal with challenging situations, and continue commitment to sustaining new behavior. Advantages of behavior change that leads to their life goals were discussed and internal rewards were reinforced to keep the study participants maintain their behavior change.

The Triple-S intervention was conducted between November 2014 and January 2015. Session format consisted of 1-hour group sections of five participants. In total, six intervention sessions were conducted with each group. A manual was created outlining Triple-S intervention. The manual was reviewed and approved by public health and 
psychology experts before being implemented. Interventionists, a psychologist, and a social worker completed Triple-S intervention training. Individual logbooks with information starting from baseline measurements were designed and used with each participant. The Stages of Change Readiness and Treatment Eagerness Scale ${ }^{21}$ was applied to assess each participant's readiness to change before each intervention session.

\section{Study design and participants}

The target population in this study was PWID aged 18-45 years in Bangkok who reported injecting any kind of illicit drugs in the past 6 months. Participants were recruited through word of mouth and an announcement posted at four PWID drop-in centers in Bangkok. These centers located not very far from each other. In total, 125 PWID were recruited and screened. Finally, 90 PWID were eligible and willing to participate in the study. They were assigned to an intervention group $(n=45)$ and a control group $(n=45)$.

This quasi-experimental study was a pre- and post-comparison with a control group design. Ninety eligible participants were assigned to one of two groups depending on the site. The intervention group was from two sites located in the center and northern part of Bangkok. They received Triple-S intervention. The control group consisted of individuals from other two sites located in the center and southern Bangkok. They only received a self-help booklet about safer injection practices at the beginning of the study. In order to have the same population characteristics for the two groups, age, sex, education, and period of drug use were matched in the sampling process. Discussions with staff members at the drop-in centers were done to consider any external factors.

The study was approved by the Ethics Committee for Research Involving Human Research Subjects, Health Science Group, Chulalongkorn University.

\section{Instruments and measures}

Trained interviewers, using structured questionnaires, collected the data. All eligible participants provided informed written consent. Participants completed interviewer-administered questionnaires that covered demographic characteristics, drug use behaviors, injecting behaviors, and harm reduction self-efficacy before attending the intervention. Follow-up assessments were conducted 3 months after the baseline measurements were taken.

The Harm Reduction Self-Efficacy Questionnaire was used to measure drug users' perceived confidence in their ability to utilize specific harm reduction strategies in three high-risk situations. These situations were experiencing withdrawal symptoms, being in a social situation where others are using unsafely, and experiencing a negative mood. It consisted of 15 harm reduction coping skills, including overdose prevention, disease prevention, and skin and vein health, resulting in 45 total items. ${ }^{21}$ The Harm Reduction Self-Efficacy Questionnaire was tested by using test-retest reliability and reported alpha scores for each condition $>0.70$.

\section{Statistical analysis}

The analysis was restricted to participants who completed both the baseline and 3-month assessment. Descriptive analyses were completed to characterize participants. A chisquare test was used to explore baseline differences between the control and intervention group. A paired $t$-test was used to explore the effects of intervention. The main outcome of interest was harm reduction self-efficacy. A $P$-value of 0.05 was used as the criterion for statistical significance for all analyses. Analyses were completed in Statistical Package for the Social Sciences version 22 (IBM Corporation, Armonk, NY, USA).

\section{Results}

Study participant enrollment and retention in the control and intervention group are shown in Figure 1. Of 90 eligible participants, a total of 63 participants completed both assessments. There were 28 participants from the control group who completed baseline and follow-up surveys and 35 participants from intervention group who completed baseline, all six sessions of Triple-S intervention and follow-up assessments.

Most of them were male ( $84 \%$ ), had a secondary school and lower education (71\%), and single (64\%) with a mean age of 41 years. They had been injecting drugs for an average of 20 years and the median of drugs injections per week was ten times in the past month. At baseline, more than half of participants (64\%) reported injecting $>1$ drug in the past month, 54\% reported mixing drugs, $43 \%$ reported injections at the groin, $65 \%$ reported rotation of injection site every time in the past month, and 30\% reported using a tourniquet in the past month. There were no significant differences on demographic characteristics between the Triple-S intervention and control groups as presented in Table 1.

Harm reduction self-efficacy was reported in three conditions: withdrawal, negative emotions, and social pressure, as presented in Table 2. The intervention group indicated an increase in harm reduction self-efficacy in negative emotional conditions from pre-intervention (mean 5.83, standard deviation [SD] 1.72) to post-intervention (mean 6.32, SD 1.39) 


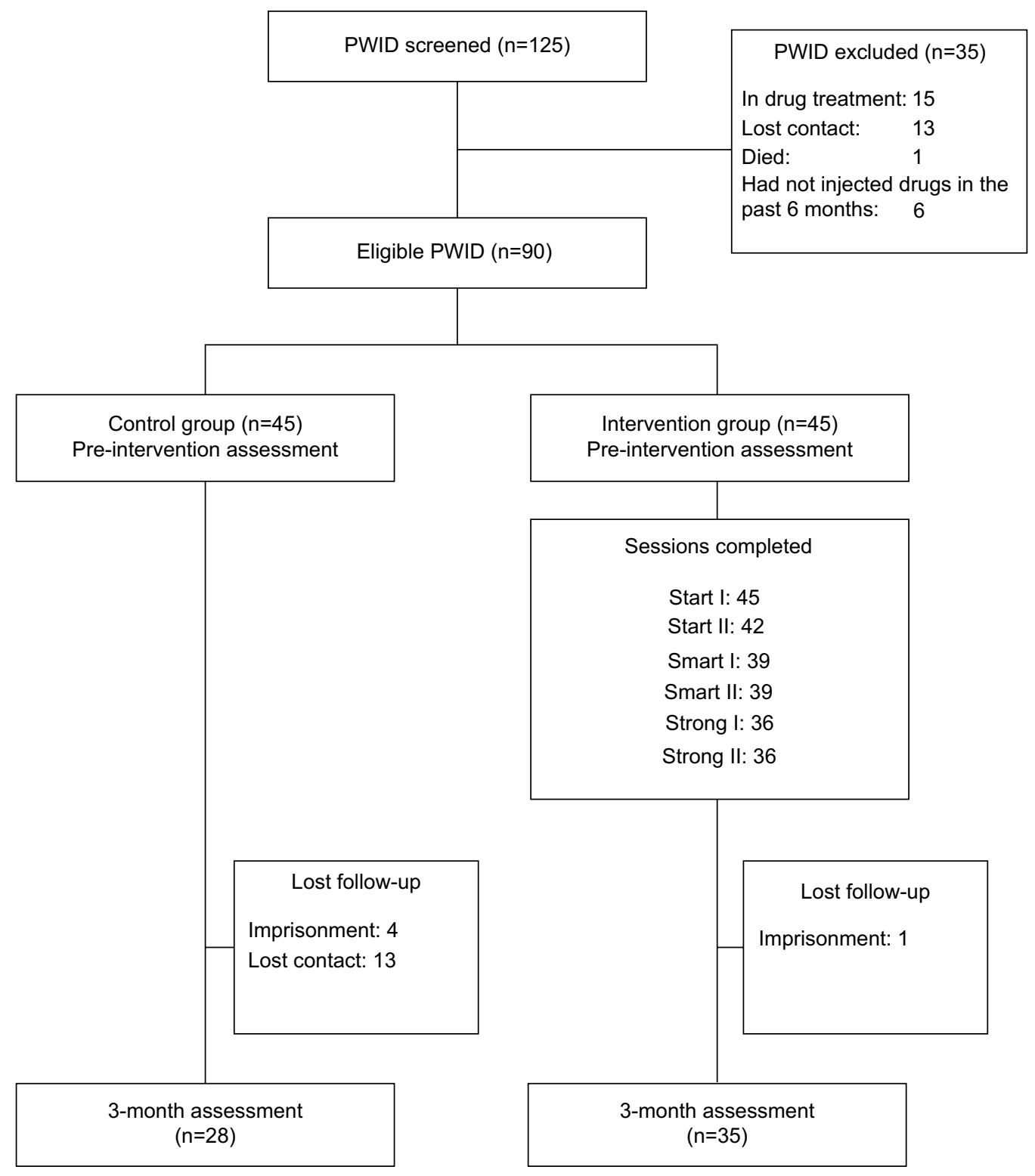

Figure I Study enrollment and retention by the study group.

Abbreviation: PWID, people who inject drugs.

while the control group remained unchanged. While the self-efficacy in social pressure conditions was not different between groups, there was a significant increase in the intervention group from pre-intervention (mean 6.09, SD 1.74) to post-intervention (mean 6.72, SD 1.40). There was no significant difference in withdrawal conditions.

\section{Discussion}

Changing the injecting behaviors of PWID who have injected drugs for a long time is a complex task. Triple-S intervention was designed to improve harm reduction self-efficacy among PWID. Self-efficacy has been reliably and significantly associated with successful efforts in initial attempts to stop drug use. ${ }^{24} \mathrm{We}$ found that an intervention group can significantly improve harm reduction self-efficacy in negative emotional conditions compared to the control group. It is considered to be an important step as studies found that negative emotions including stress and anxiety play a key role in drug dependence. ${ }^{25,26}$ Both intervention and control groups demonstrated highest scores on harm reduction self-efficacy in social pressure conditions; however, social network characteristics such as family member using injections, using injections with the sexual partner have been associated with unsafe injection behaviors. ${ }^{27}$ Regarding withdrawal condition, there may be other factors related to the improvement of self-efficacy including participants' past experiences with 
withdrawal. During the severity of withdrawal symptom, PWID are more likely to have risky injection behaviors and overcoming withdrawal becomes a challenging priority. ${ }^{28}$

Self-efficacy is an important factor toward drug use behavior change and other treatment outcomes. ${ }^{29-31}$ The results of the present study may be taken to suggest the importance of behavior change intervention implemented with PWID, especially integrated with services provided by drop-in centers where PWID can be reached voluntarily. Triple-S intervention can be further developed to cover other harm reduction behaviors and improve harm reduction selfefficacy in all three conditions. Harm reduction programs in different contexts may provide a range of services that include the provision of injection equipment, education, and information on reduction of drug-related harms, overdose prevention, referral to drug treatment, medical care, and legal and social services.

Table I Demographic characteristics of study participants by the study group

\begin{tabular}{|c|c|c|c|}
\hline Characteristics & $\begin{array}{l}\text { Control } \\
\text { group }(n=28)\end{array}$ & $\begin{array}{l}\text { Intervention } \\
\text { group }(n=35)\end{array}$ & $P$-value \\
\hline Sex & & & 0.543 \\
\hline Male & $24(86 \%)$ & 29 (83\%) & \\
\hline Female & $4(14 \%)$ & $6(17 \%)$ & \\
\hline Age (years) & & & 0.220 \\
\hline$\leq 39$ & 17 (6I\%) & I8 (5 I\%) & \\
\hline$>39$ & II (39\%) & 17 (49\%) & \\
\hline Education & & & 1.000 \\
\hline $\begin{array}{l}\text { Secondary school and } \\
\text { lower }\end{array}$ & 20 (7I\%) & 25 (7I\%) & \\
\hline $\begin{array}{l}\text { Higher than secondary } \\
\text { school }\end{array}$ & 8 (29\%) & $10(29 \%)$ & \\
\hline Marital status & & & 0.206 \\
\hline Married & $9(32 \%)$ & I 4 (40\%) & \\
\hline $\begin{array}{l}\text { Single/divorced/ } \\
\text { separated/ } \\
\text { widowed }\end{array}$ & $19(68 \%)$ & $21(60 \%)$ & \\
\hline $\begin{array}{l}\text { Period of injecting } \\
\text { drugs (years) }\end{array}$ & & & 0.573 \\
\hline$<20$ & II (39\%) & 15 (43\%) & \\
\hline$\geq 20$ & 17 (61\%) & $20(57 \%)$ & \\
\hline
\end{tabular}

\section{Limitations}

It is important to consider the limitations of this study. First, due to the illegal nature and the rarity of injection drug use, we found barriers in the recruitment of the sample group. This study aimed to test the effectiveness of the intervention; therefore, measures were taken to prevent bias by screening out those who were in any kind of treatment. These measures contributed to the difficulty in recruitment and small sample size as around half of PWID in Bangkok reported to be receiving treatment. ${ }^{32}$ Second, the study could not randomize individual PWID to the study. Instead, PWID were assigned to groups depending on site location. Efforts were made to match the demographic characteristics of both groups in the sampling process, and it can be found that there was no significant difference between groups. Finally, for ethical reasons, information to identify candidates could not be collected. Therefore, it was difficult to conduct follow-ups for the 3 -month assessment. There was a follow-up loss rate of $30 \%$.

\section{Conclusion}

Findings suggest that Triple-S intervention can significantly improve harm reduction self-efficacy in negative emotional conditions. The results of the present study may be taken to suggest the importance of behavior change intervention implemented with PWID, especially integrated with services provided by drop-in centers where PWID can be reached voluntarily. Triple-S intervention can be further developed to cover other harm reduction behaviors and improve harm reduction self-efficacy in all three conditions.

\section{Acknowledgments}

The study was supported by the 90th Anniversary Fund of Chulalongkorn University (Ratchadaphiseksomphot Endowment Fund). We would like to thank the members of the PWID community in Bangkok who agreed to participate in the survey. Managers and staff members of the Ozone Foundation and Raks Thai Foundation supported the data collection process.

Table 2 Pre- and post-intervention effects on harm reduction self-efficacy among PWID

\begin{tabular}{|c|c|c|c|c|c|c|c|}
\hline \multirow[t]{2}{*}{ HRSEQ score } & \multicolumn{2}{|c|}{ Control group $(n=28)$} & \multirow{2}{*}{$\begin{array}{l}\text { Pre/post } \\
\text { P-value }^{\text {a }}\end{array}$} & \multicolumn{2}{|c|}{ Intervention group $(n=35)$} & \multirow{2}{*}{$\begin{array}{l}\text { Pre/post } \\
\text { P-value }^{\text {a }}\end{array}$} & \multirow{2}{*}{$\begin{array}{l}\text { Control vs } \\
\text { intervention } P \text {-value }\end{array}$} \\
\hline & $\begin{array}{l}\text { Baseline, } \\
\text { mean (SD) }\end{array}$ & $\begin{array}{l}\text { 3-month, } \\
\text { mean (SD) }\end{array}$ & & $\begin{array}{l}\text { Baseline, } \\
\text { mean (SD) }\end{array}$ & $\begin{array}{l}\text { 3-month, } \\
\text { mean (SD) }\end{array}$ & & \\
\hline $\begin{array}{l}\text { HRSEQ - } \\
\text { withdrawal }\end{array}$ & $5.54(1.55)$ & $5.38(1.34)$ & 0.426 & $5.57(\mathrm{I} .47)$ & $5.99(1.48)$ & 0.074 & 0.067 \\
\hline $\begin{array}{l}\text { HRSEQ - negative } \\
\text { emotions }\end{array}$ & $5.76(1.59)$ & $5.74(1.37)$ & 0.893 & $5.83(1.72)$ & $6.32(1.39)$ & 0.016 & 0.048 \\
\hline $\begin{array}{l}\text { HRSEQ - social } \\
\text { pressure }\end{array}$ & $5.76(1.52)$ & $6.02(1.52)$ & 0.269 & $6.09(1.74)$ & $6.72(1.40)$ & 0.012 & 0.827 \\
\hline
\end{tabular}




\section{Disclosure}

The authors report no conflicts of interest in this work.

\section{References}

1. UNODC. World Drug Report 2015. Vienna, Austria: UNODC; 2015. Available from: https://www.unodc.org/documents/wdr2015/World_ Drug_Report_2015.pdf. Accessed August 16, 2016.

2. WHO. A Strategy to Halt and Reverse the HIV Epidemic Among People Who Inject Drugs in Asia and the Pacific 2010-2015. Manila, Philippines: WHO; 2010. Available from: https://www.unodc.org/documents/ southeastasiaandpacific/2010/07/hiv-strategy/Harm_Reduction_Strategy_Asia_Pacific.pdf. Accessed August 16, 2016.

3. EMCDDA. Trends in Injecting Drug Use in Europe. Lisbon, Portugal: EMCDDA; 2010. Available from: http://www.emcdda.europa.eu/ attachements.cfm/att_108590_EN_EMCDDA_SI10_injecting.pdf. Accessed August 16, 2016.

4. WHO. HIV/AIDS Care and Treatment for People Who Inject Drugs in Asia and the Pacific: An Essential Practice Guide. Manila, Philippines: WHO; 2008. Available from: http://www.who.int/hiv/pub/idu/ idu_searo_wpro_treatment.pdf. Accessed August 16, 2016.

5. Aramrattana A, et al. Using the multiplier method to estimate the population size of injecting drug users (IDUs) in Thailand, 2009. In: The 10th International Congress on AIDS in Asia and the Pacific; August 26-30, 2011; Busan, Republic of Korea.

6. Johnston LG, Prybylski D, Raymond HF, Mirzazadeh A, Manopaiboon $\mathrm{C}, \mathrm{McF}$ arland $\mathrm{W}$. Incorporating the service multiplier method in respondent-driven sampling surveys to estimate the size of hidden and hard-to-reach populations: case studies from around the world. Sex Transm Dis. 2013;40(4):304-310.

7. WHO. ATLAS of Substance Use Disorders, Country Profile: Thailand. WHO; 2010. Available from: http://www.who.int/substance_abuse/publications/atlas_report/profiles/thailand.pdf. Accessed August 16, 2016.

8. HIV/AIDS TRaC among Injecting Drug Users Third Round. Population Services International; 2008.

9. Ti L, Hayashi K, Kaplan K, Suwannawong P, Wood E, Kerr T. Groin injecting among a community-recruited sample of people who inject drugs in Thailand. Subst Abuse Treat Prev Policy. 2014;9:4.

10. Baker A, Lee NK, Claire M, et al. Brief cognitive behavioural interventions for regular amphetamine users: a step in the right direction. Addiction. 2005;100(3):367-378.

11. Jonathan R, Hugh A, Hickman M. A systematic review of interventions to increase the uptake of opiate substitution therapy in injecting drug users. J Public Health (Oxf). 2011;33(3):378-384.

12. Smedslund G, Berg, RC, Hammerstrøm KT, Steiro A, Leiknes KA, Dahl HM, Karlsen K. Motivational interviewing for substance abuse. Cochrane Database Syst Rev. 2011;(5):CD008063.

13. Niaura R. Cognitive social learning and related perspectives on drug craving. Addiction. 2000;95(Suppl 2):S155-S163.

14. Bandura A. Self-efficacy: toward a unifying theory of behavior change Psychol Rev. 1977;84(2):191-215.

15. World Bank. Theories of Behavior Change. Technical Briefs, CommGAP. Washington, DC: World Bank; 2009.

16. Kaddena RM, Litt MD. The role of self-efficacy in the treatment of substance use disorders. Addict Behav. 2011;36(12):1120-1126.
17. Tatarsky A. Harm reduction psychotherapy: extending the reach of traditional substance use treatment. $J$ Subst Abuse Treat. 2003;25(4):249-256.

18. Wilsona DP, Donald B, Shattock AJ, Wilson D, Fraser-Hurt N. The costeffectiveness of harm reduction. Int J Drug Policy 2015;26(Suppl 1): S5-S11.

19. Non Prescription Needle Use Initiative. Working with People Who Use Drugs: A Harm Reduction Approach. Edmonton, AB, Canada: Non Prescription Needle Use Initiative; 2007. Available from: http://www. liver.ca/files/PDF/Publications_English/Working_with_People_who_ Use_Drugs-A_Harm_Reduction_Approach_Manual_and_all_supplements.pdf. Accessed August 16, 2016.

20. Harm Reduction Coalition. Guide to Developing and Managing Overdose Prevention and Take-Home, Naloxone Projects. Harm Reduction Coalition; 2012. Available from: http://harmreduction.org/wp-content/ uploads/2012/11/od-manual-final-links.pdf. Accessed August 16, 2016.

21. Phillips KT. Applying the Relapse Model to Harm Reduction: The Development and Evaluation of the Harm Reduction Self-efficacy Questionnaire [PhD thesis]. Bowling Green, OH: Bowling Green State University; 2005.

22. Abdollahi Z, Taghizadeh F, Hamzehgardeshi Z, Bahramzad O. Relationship between addiction relapse and self-efficacy rates in injection drug users referred to Maintenance Therapy Center of Sari. Glob J Health Sci. 2014;6(3):138-144.

23. Hayashi K, Ti L, Fairbairn N, Kaplan K, Suwannawong P, Wood E, Kerr T. Drug-related harm among people who inject drugs in Thailand: summary findings from the Mitsampan Community Research Project. Harm Reduct J. 2013;10:21.

24. Marlatt GA, Baer JS, Quigley LA. Self-efficacy and addictive behavior. In: Bandura A, editor. Self-efficacy in Changing Societies. New York: University Press; 1995:289-315.

25. Wang Y, Chen X. Stress and alcohol use in rural Chinese residents: a moderated mediation model examining the roles of resilience and negative emotions. Drug Alcohol Depend. 2015;155:76-82.

26. Drapela LA. The effect of negative emotion on licit and illicit drug use among high school dropouts: an empirical test of general strain theory. J Youth Adolesce. 2006;35(5):752-767.

27. Gupta SK, Ambekar A, Dhawan A, Mehta M. Psychosocial factors associated with HIV-related high-risk injection behavior among people who inject drugs. J Ment Health Human Behav. 2014;19(2):62-68.

28. Mateu-Gelabert P, Friedman SR, Sandoval M, Wendel T, Meylakhs P. Strategies to avoid opiate withdrawal: implications for HCV and HIV risks. Int J Drug Policy. 2010;21(3):179-185.

29. Dolan SL, Martin RA, Rohsenow DJ. Self-efficacy for cocaine abstinence: pretreatment correlates and relationship to outcomes. Addict Behav. 2008;33(5):675-688.

30. Hayaki J, Herman DS, Hagerty CE, de Dios MA, Anderson BJ, Stein MD. Expectancies and self-efficacy mediate the effects of impulsivity on marijuana use outcomes: an application of the acquired preparedness model. Addict Behav. 2011;36(4):389-396.

31. Caviness CM, Hagerty CE, Anderson BJ, de Dios MA, Hayaki J, Herman D, Stein MD. Self-efficacy and motivation to quit marijuana use among young women. Am J Addict. 2013;22(4):373-380.

32. Fairbairn N, Hayashi K, Kaplan K, Suwannawong P, Qi J, Wood E, Kerr T. Factors associated with methadone treatment among injection drug users in Bangkok, Thailand. J Subst Abuse Treat. 2012;43(1): 108-113.
Psychology Research and Behavior Management

\section{Publish your work in this journal}

Psychology Research and Behavior Management is an international, peerreviewed, open access journal focusing on the science of psychology and its application in behavior management to develop improved outcomes in the clinical, educational, sports and business arenas. Specific topics covered in the journal include: Neuroscience, memory and decision making; Behavior

\section{Dovepress}

modification and management; Clinical applications; Business and sports performance management; Social and developmental studies; Animal studies. The manuscript management system is completely online and includes a very quick and fair peer-review system, which is all easy to use. Visit http://www. dovepress.com/testimonials.php to read real quotes from published authors. 